\title{
EVOLUÇÃO DA DIVERSIDADE VEGETAL ARBÓREA EM UM PARQUE CENTENÁRIO
}

\author{
Henrique Sundfeld Barbin ${ }^{1}$, Valdemar Antonio Demétrio ${ }^{2}$
}

\section{RESUMO}

No presente estudo, utilizaram-se de levantamentos florísticos realizados em 1965 e 1991, projeto paisagístico e fotografias aéreas verticais de épocas distintas, para acompanhar as transformações ocorridas nos maciços vegetais do Parque da Escola Superior de Agricultura "Luiz de Queiroz" (ESALQ), da Universidade de São Paulo (USP), em Piracicaba, São Paulo, Brasil. O Parque, de $15.000 \mathrm{~m}^{2}$, construído no Estilo Inglês de Paisagismo, foi implantado ao redor de 1907 e teve crescimento descontrolado e demasiado das áreas de seus maciços. Os levantamentos florísticos foram digitados no software Access. Pelos resultados obtidos em 1965, o Parque era formado por 444 indivíduos arbóreos, sendo este valor aumentado para 2.904, em 1991. Com relação às espécies arbóreas encontradas, em 1965, existiam 241 espécies no Parque, diminuindo em 1991, para 215. Há grande domínio, em número de indivíduos, de algumas espécies e a formação de reboleiras. Através de confrontos realizados, utilizando-se do software Access, nota-se a extinção de 154 espécies arbóreo/arbustivas e incremento de outras 124, estando apenas 90 espécies, presentes nos dois levantamentos (1965 e 1991). Todos estes fatos indicam a necessidade de um manejo adequado e urgente dos maciços vegetais do Parque da ESALQ, para evitar maior descaracterização.

Palavras-Chave: Parque da ESALQ, diversidade vegetal, manejo

1 Eng. Agrônomo. Doutor em Fitotecnia. Rua Miguel Antonio Gonçalves, 724. Piracicaba - SP

${ }^{2}$ Eng. Agrônomo. Professor Titular do Departamento de Engenharia Rural da Escola Superior de Agricultura "Luiz de Queiroz". USP. 


\title{
BOTANIC EVOLUTION IN A CENTENNIAL PARK
}

\begin{abstract}
Floristic surveys in 1965 and 1991, aerophotography and landscape project were used to assess the transformations on plant diversity of the Park of "Escola Superior de Agricultura Luiz de Queiroz (ESALQ)", University of São Paulo (USP), in Piracicaba, State of São Paulo, Brazil. The 15.000 $\mathrm{m}^{2}$ Park was built in the English Landscape Style, in 1907 and ever since no management on the growth of tree groupments was observed.. The 1965 floristic survey showed that the Park was formed by 444 tree/shrub species, increasing to 2,904 ones in the 1991 floristic survey. In the 1965 survey one found 241 tree/shrub species but this number decreased to 215 species in 1991, with an increasing dominance of some species. The extinction of 154 tree/shrub species and the increment of 124 new ones was observed. Only 90 species were common in both surveys (1965 and 1991). Such data indicate the need of an urgent management of the Park.
\end{abstract}

Key Words: ESALQ Park, plant diversity, management

\section{INTRODUÇÃO}

O Parque da Escola Superior de Agricultura "Luiz de Queiroz" (ESALQ), da Universidade de São Paulo (USP), em Piracicaba, SP, apresenta uma coleção de espécies botânicas, regionais e exóticas, além de possuir grande valor científico e histórico. O mesmo foi idealizado pelo arquiteto e paisagista belga Arsênio Puttemans e inaugurado em meados de 1907, estando, portanto, prestes a completar 100 anos.

Sua conservação como patrimônio histórico é muito importante, já que há poucas obras realizadas pelo paisagista no Brasil e, ainda, o Parque da ESALQ é hoje um dos que mantiveram a maioria das características 
propostas (Lima, 1987). O local onde foi construído o Parque, apresentava precárias condições pedológicas, tendo sido necessário um árduo trabalho de troca e acréscimo de solo, uma vez que a poucos centímetros de profundidade havia folhelhos de formação Corumbataí.Não se sabe da existência de lista ou sugestão feita pelo idealizador do projeto paisagístico referente às espécies vegetais a serem utilizadas no mesmo, nem catalogação das plantas que foram colocadas na área. Devido à importância do Parque e a necessidade de se conhecer seu potencial botânico, em 1965, Manoel Fadigas, pesquisador do Instituto Agronômico de Campinas (IAC), foi requisitado pela ESALQ para realizar um levantamento florístico e fitossociológico nos diversos maciços do Parque, porém o mapa de localização dos espécimes não foi localizado sendo uma grande perda para o patrimônio da Escola e do país. Sua falta acaba por anular a fitossociologia das plantas catalogadas. Entre 1990 e 1992, alunos da Escola, sob orientação dos professores do Departamento de Botânica, realizaram um novo levantamento florístico e fitossociológico dos maciços.

O objetivo deste estudo é conhecer as mudanças ocorridas ao longo dos anos, para fornecer material de apoio às ações futuras de manejo da área.

\section{MATERIAL E MÉTODOS}

O Parque, de 15 ha, está localizado na Escola Superior de Agricultura Luiz de Queiroz, da Universidade de São Paulo, Campus de Piracicaba, situado à latitude $22^{\circ} 42^{\prime} 30,9^{\prime \prime} \mathrm{S}$ e longitude $47^{\circ} 38^{\prime} 01,2^{\prime \prime W}$ e está a $547 \mathrm{~m}$ de altitude. Segundo a classificação de Köpen, o clima é do tipo Cwa (Setzer, 1946). Já a vegetação característica da região é a Floresta Estacional Semidecídua, (IBGE, 2004). Sendo o terreno sobre o qual foi implantado, um aterro, não se enquadrou em nenhuma classificação de solo. 
Para o desenvolvimento deste trabalho, foram utilizados: levantamentos florísticos realizados em 1965 e 1991, software Access, projeto original do Parque, fotografias aéreas verticais dos anos de 1962 e 1993 e farto material bibliográfico. Pela não existência da planta baixa de localização física das espécies arbóreas e arbustivas, no levantamento de 1965, a análise teve que ser feita considerando-se o Parque como um todo, não podendo, portanto, utilizar a fitossociologia, o que permitiria levantar as mudanças ocorridas em cada maciço. Os nomes das espécies encontradas nos levantamentos florísticos de 1965 e 1991 foram revisados e atualizados quando necessário, por meio de consulta ao seguinte material bibliográfico: Rossi, 1987; Tozzi, 1989; Mesquita, 1990; Souza, 1990; Lorenzi, 1992; Romero, 1993; Sartori, 1994; Lorenzi, Souza, 1995; Henderson et al., 1995; Barreto, 1997; Mabberley, 1997; e Lorenzi, 1998. Os dados obtidos, após revisão e atualização, foram digitados no Software Access 2.0, no qual se montou, para cada levantamento, uma tabela. Um confronto de espécies presentes no Parque nas épocas estudadas foi realizado.

\section{RESULTADOS E DISCUSSÃO}

A falta de registros escritos das espécies implantadas na época da fundação do parque não permitiu o acompanhamento da evolução e comportamento das plantas no período desejado. A primeira catalogação das árvores encontradas no parque que se teve notícia e que pôde ser resgatado foi realizada apenas em 1965, quando o Parque já se encontrava com 57 anos. Estima-se que inúmeras mudanças devam ter ocorrido na vegetação neste período. Há, porém, registros fotográficos, mas sem data e de autoria desconhecida, que mostram várias plantas locadas nos maciços e em grupos na época da implantação do Parque (Fig. 1) e, em outra época (Fig. 2), também de data e autor desconhecidos, mostrando, em segundo plano, alguns guapuruvus (Schizolobium parahyba) em estágio avançado de 
crescimento e ao fundo, a vegetação dos mesmos maciços da Figura 1, já formada. Com relação ao catalogado, ocorreram inúmeras mudanças na botânica do Parque, tanto em quantidade de indivíduos arbóreos, quanto em número de espécies presentes. Pode-se notar no levantamento florístico realizado em 1965 que havia 444 indivíduos arbóreos e, em 1991, 2.904, portanto, praticamente seis vezes mais árvores que no primeiro. Quanto à diversidade biológica, houve diminuição no número de espécies arbóreas de um levantamento para o outro. Em 1965, 241 espécies foram catalogadas e em 1991 apenas, 215. Esses dados são muito preocupantes, notando-se, ainda, a presença de reboleiras em alguns maciços, onde ocorre grande domínio de algumas espécies sobre outras. No período estudado, 154 espécies foram extintas da área em estudo e outras 124 foram incorporadas. Um total de apenas 90 árvores aparece nos dois levantamentos. Das espécies extintas a maior parte eram plantas do grupo das clímax e secundárias tardias e as incorporadas, em grande parte do grupo das pioneiras e secundárias iniciais, o que põe em risco a sobrevivência da mata, segundo farta literatura. $\mathrm{O}$ crescimento descontrolado dos maciços, além de causar o dano na biodiversidade, está também descaracterizando um projeto centenário de um Parque de extrema valia à ciência, ao paisagismo e à contemplação de visitantes do mundo todo que o freqüentam periodicamente e/ou por aqui passaram. Quando se analisa o espaço físico e as características propostas pelo paisagista, quando da elaboração do projeto, nota-se que os maciços arbóreos estão crescendo demasiadamente, invadindo a área onde foram projetados extensos gramados e englobando as árvores isoladas e dispostas em pequenos grupos, característica do estilo paisagístico inglês, formando grandes maciços. Imprescindível lembrar que todo projeto paisagístico deve ter suas características mantidas, inclusive a conformação de seus canteiros e maciços. O crescente aumento dos maciços e desequilíbrio das espécies pode ser explicado pelo grande número de 
plantios que são realizados por visitantes e moradores da região que trazem mudas no intuito de contribuir com o desenvolvimento do Parque e as plantam sem autorização dos responsáveis pela manutenção do mesmo e em local qualquer, não respeitando e/ou desconhecendo as diretrizes paisagísticas propostas e da biodiversidade. O plantio de árvores na época das formaturas dos cursos da Escola, realizado por um longo período na área do Parque, onde as mudas eram locadas geralmente no perímetro dos maciços e/ou entre seus canteiros, também contribuíram para o crescimento e união dos maciços. Essas mudas, a medida que cresceram, formaram suas copas sobre o gramado, sombreando-o e diminuindo sua área. Ao longo dos anos, a grama morreu e no local, foram criados serrapilheira e banco de sementes, que deram oportunidade a outras sementes germinarem, repetindo o processo e aumentando ainda mais a área do maciço. Um outro fator importante é o processo natural de propagação. Há na região diversos bosques e matas ciliares, tais como a Mata do Rio Piracicamirim e a Mata da Pedreira, que formam uma grande mancha verde englobando o Parque e merecem ser considerados no fornecimento de propágulos e sementes. É sabido que um grande número de pássaros, mamíferos e répteis, circula entre estas matas e devem também ser responsáveis pelas grandes mudanças ocorridas em tão pouco tempo. Um estudo da mobilidade desses animais deve ser realizado, na tentativa de se conhecerem os efeitos causados e propor manejo dos mesmos. Animais domésticos, principalmente gatos, são criados nas dependências do Parque onde não raro são vistos perturbando e até caçando os animais selvagens, interferindo nos processos naturais. Deve se estudar o grau de influência desses animais e caso necessário, os mesmos devem ser retirados. Muitas ações antrópicas principalmente nos finais de semana e férias escolares, onde um grande número de visitantes procura o Parque para práticas de lazer, passivo e ativo, também deve ser considerado e estudado no que se refere ao desequilíbrio da fauna e da flora. 
Propõe-se, portanto, um manejo racional nos maciços estudados, para que haja maior equilíbrio entre as espécies, por meio da retirada de árvores de espécies que estão dominando - tais como Johanesia princeps (Boleira), Holocalix balansae (Alecrim-de-Campinas), Anadenanthera $s p$. (Angico), Myrcia laurotteana (Cambui), Casearina silvestris (Guaçatonga), Allophylus edulis (Chal-chal), Machaerium villosum (Jacarandá-paulista), Aspidosperma ramiflorum (Guatambu), Rhamnidium aleocarpum (Saguaragi), além de algumas espécies de palmeiras, dentre elas Syagrus romanzoffiana (Jerivá) e algumas espécies de pinheiros. Devem-se realizar desbastes de árvores de espécies que estiverem desequilibrando a biodiversidade nos maciços e evitando o plantio de árvores nos locais onde os maciços foram corrigidos. No interior dos maciços, devem ser introduzidas árvores de espécies que foram extintas no período estudado, observando a fitossociologia de cada espécie, para auxiliar a sua distribuição. Devem ser introduzidas, também, espécies que sejam de interesse para estudos e pesquisas e, ainda, plantas de espécies presentes no Parque representadas por apenas um indivíduo, que esteja danificado, doente, praguejado ou com idade avançada. A fim de tentar proporcionar um equilíbrio ecológico, espécies que atraiam/mantenham a fauna devem ser introduzidas. Há um grande desafio na manutenção das características propostas para a área uma vez que a falta de espaços livres públicos destinados ao lazer da população e o fato de o Parque estar inserido na malha urbana do município o tornam espaço de grande visitação e pressão antrópica, inclusive as áreas dos maciços arbóreos apesar da legislação específica que rege o Parque e o seu tombamento junto ao CONDEPHAT. Ações protetoras são de extrema importância para o sucesso de qualquer intervenção benéfica que venha a ser implantada. Por meio dos dados analisados, pode se verificar que, em 24 anos, ocorreram muitas mudanças na estrutura da mata, fato preocupante para o futuro do Parque, pois, a 
biodiversidade está diminuindo e espécies únicas estão dominando os maciços. O parque é fruto de um reflorestamento e não um remanescente de floresta nativa, mas já possui relações entre espécies diferentes das que ocorrem dentro de um remanescente de mata. Além disso, as técnicas hoje conhecidas de reflorestamento, tais como os processos sucessionais, agentes dispersores, etc., muito provavelmente, não foram previstos na implantação do projeto. Seria de extrema valia, para um estudo como este, se houvesse a relação de plantas utilizadas na época da implantação do projeto ou, ainda, se houvesse levantamentos de todas as espécies, tais como os citados neste trabalho, realizados em tempos anteriores.

Tabelas contendo as espécies e as quantidades de indivíduos, resultante dos levantamentos florísticos, bem como lista detalhada de árvores e arbustos que foram extintas, acrescentadas e mantidas no Parque podem ser visualizados na dissertação de mestrado de Barbin localizada no endereço: www.teses.usp.br.

\section{REFERÊNCIAS BIBLIOGRÁFICAS}

BARBIN, H. S. Estudo das transformações na conformação dos maciços arbóreos/arbustivos do Parque da Escola Superior de Agricultura 'Luiz de Queiroz' - Universidade de São Paulo, através de fotografias aéreas verticais e levantamentos florísticos de épocas distintas. Piracicaba: USP, 1999. 94p. Dissertação (Mestrado) Departamento de Produção Vegetal, Escola Superior de Agricultura Luiz de Queiroz (ESALQ). BARRETO, R.G. Levantamento das espécies de Commelinaceae R. Br. Nativas do Brasil. São Paulo: EDUSP, 1997. 490p. Tese (Doutorado) Instituto Biológico, Universidade de São Paulo.

HENDERSON, A.; GALEANO, G.; BERNAL, R. Field guide to the palms of the Americas. New Jersey: Princeton University Press. 1995. $416 \mathrm{p}$. 
IBGE (Instituto Brasileiro de Geografia e Estatística), Mapa de Vegetação do Brasil. 2004.

LIMA, A. M. L. P. Nosso Parque faz oitenta anos. Revista da ADEALQ, v. 10, n.6, p20-22, 1987.

LORENZI, H. Árvores Brasileiras. Manual de identificação e cultivo de plantas arbóreas nativas do Brasil. Nova Odessa: Editora Plantarum, 1992. 368p.

LORENZI, H. Árvores Brasileiras. Manual de identificação e cultivo de plantas arbóreas nativas do Brasil. 2ed. Nova Odessa: Editora Plantarum, 1998. 320.

LORENZI, H.; SOUZA, H., M.; COSTA, J. T. de M. et al. Palmeiras do

Brasil. Nativas e exóticas. Nova Odessa: Editora Plantarum, 1996. $320 \mathrm{p}$.

MABBERLEY, D. J. The plant-book, a portable dictionary of the vascular plants. 2ed. New York: Cambridge University Press. 1997. $858 \mathrm{p}$.

MESQUITA, A. de L. Revisão taxonômica de Gênero Enterolobium Mart. (Mimosoideae) para a região neotropical. Recife: UFRP. 1990. 222p. Dissertação (Mestrado) - Universidade Federal Rural de Pernambco.

ROMERO, R. Florística da Família Melastomataceae na planície litorânea de Picinguaba, Município de Ubatuba, Parque Estadual da Serra do Mar, São Paulo. Rio Claro: UNESP. 1993. 178p. Dissertação (Mestrado) - Instituto de Biociências, Universidade Estadual Paulista.

ROSSI, L. A flora arbóreo-arbustiva da Mata da Reserva da Cidade Universitária "Armando de Salles Oliveira", São Paulo. São Paulo: USP, 1987. 270p. Dissertação (Mestrado) - Instituto de Biociências, Universidade de São Paulo.

SARTORI, L. B. S. O gênero Machaerium Pers. (Leguminosae Papilionidae - Dalbergieae) no Estado de São Paulo. Campinas: 
UNICAMP, 1994. 101p. Dissertação (Mestrado) - Instituto de Biologia,

Universidade Estadual de Campinas.

\section{SETZER, J. Contribuição para o estudo do clima do Estado de São}

Paulo. D.E.R. São Paulo. IX a XI: 237p. 1946. (separata).

SOUZA, C. S. Scrophilariaceae da Serra do Cipó, Minas Gerais, Brasil. São

Paulo: USP. 1990. 339p. Dissertação (Mestrado) - Departamento de

Botânica, Universidade de São Paulo.

TOZZI, A. M. G. de A. Estudo taxonômico dos Gêneros Lonchocarpus

Kunth e Deguelia Aubl. No Brasil. Campinas: UNICAMP. 1989. $341 \mathrm{p}$.

Tese (doutorado) - Universidade Estadual de Campinas. 


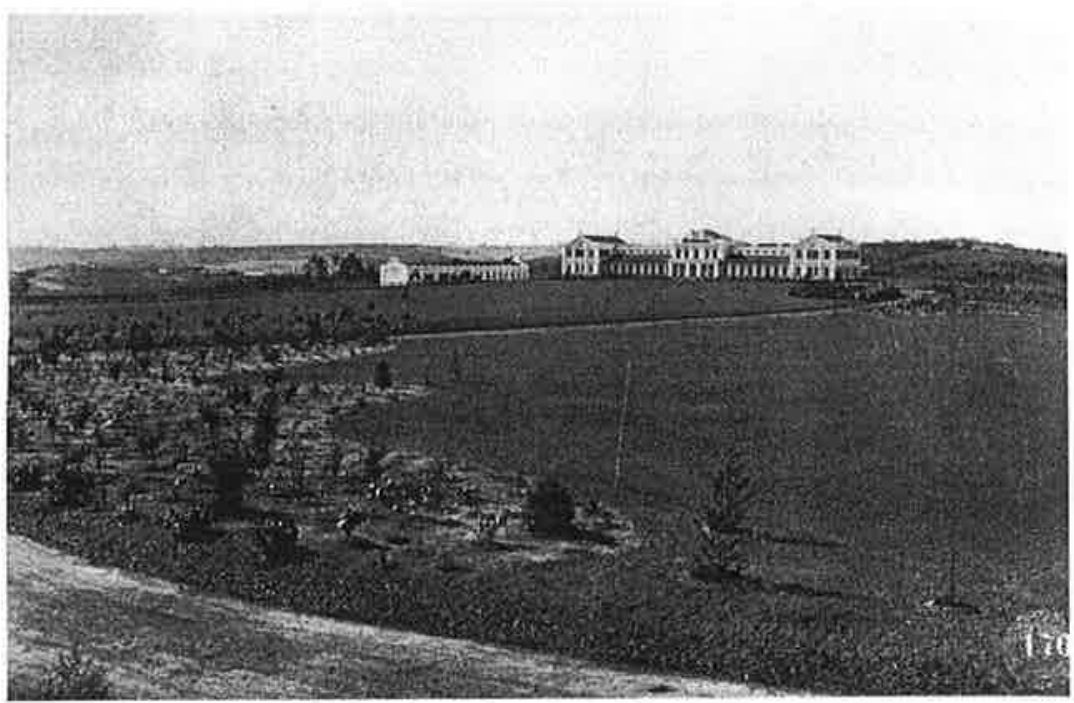

Figura 1.Foto tirada logo após a implantação do Parque. (sem autor ou data)

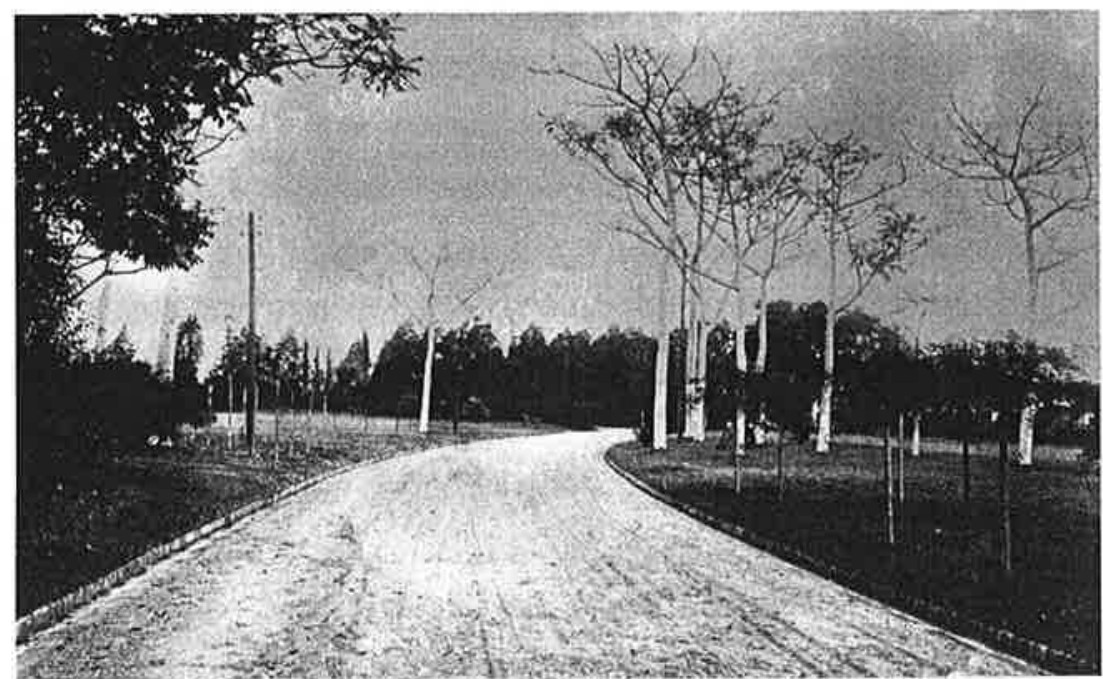

Figura 2. Foto de Guapuruvus (Schizolobium parahyba), após a implantação do Parque (sem autor ou data). 